\title{
ABSTRAK \\ PENGARUH PEMBERIAN KOMPRES AIR HANGATTERHADAP PENGURANGAN RASA NYERI PADA IBU BERSALIN DI PUSKESMAS PEKKABATA
}

\author{
Rosdiana $^{1}$, Sumiyati ${ }^{2}$, Nurul Azharia ${ }^{3}$, Hijrah $^{4}$ \\ $($ xxi +66 halaman +9 tabel +4 gambar +8 lampiran $)$
}

Latar Belakang : Sebagian besar ibu bersalin mengalami rasa nyeri pada waktu melahirkan, tetapi intensitasnya rasa nyeri ini berbeda pada setiap ibu bersalin. Metode non farmakologis merupakan metode yang paling sering digunakan untuk mengurangi nyeri. Dari data yang diperoleh di Puskesmas Pekkabata pada tahun 2016 jumlah ibu bersalin sebanyak 450 orang dan pada tahun 2017 terhitung sejak bulan Oktober - Desember sebanyak 29 ibu bersalin sehingga peneliti tertarik untuk meneliti Gambaran pengetahuan ibu tentang Pneumonia pada balita di Puskemas Pekkabata tahun 2016.

Tujuan Penelitian : Untuk mengetahui Pengaruh Pemberian kompres air hangat terhadap pengurangan rasa nyeri pada ibu bersalin di Puskesmas Pekkabata.

Metode Penelitian : yang digunakan adalah quasy eksperimentaldesign/eksperimen semu, yaitu penelitian eksperimen yang dilaksanakan pada satu kelompok saja yang dinamakan kelompok eksperimen tanpa ada kelompok pembanding atau kelompok kontrol (Arikunto, 2012). Populasi dalam penelitian ini semua ibu bersalindi Puskesmas Pekkabata pada tahun 2017 terhitung sejak bulan oktober-desember sebanyak 29 orang.Pemilihan sampel dalam penelitian ini adalah menggunakan Accidental Sampling yaitu pengambilan sampel yang dilakukan dengan kebetulan bertemu.Banyaknya sampel dalam penelitian ini adalah sebanyak 29 responden.

Hasil penelitian : Uji statistic menggunakan Marginal Homogeneity Test juga mendukung data pada table dimana dari hasil diperoleh pvalue $=0,000$ (Pvalue $<0,05)$ maka ini berarti $\mathrm{H}_{\mathrm{a}}$ diterima dan $\mathrm{H}_{0}$ ditolak dapat disimpulkan bahwa ada Pengaruh Pemberian kompres air hangat terhadap pengurangan rasa nyeri pada ibu bersalin di Puskesmas Pekkabata.

Kesimpulan :adanya pengurangan nyeri setelah dilakukan kompres air hangat pada ibu bersalin.

Kata Kunci : Pengaruh, Kompres air hangat, nyeri, ibu bersalin.

Daftar Pustaka :17 Buku + 6 internet (2008-2017)

\section{ABSTRACT \\ EFFECT OF GIVING WARM WATER COMPRESSES ON PAIN TREATMENT \\ IN THE MOTHER OF HEALTH IN THE HEALTH CENTER PEKKABATA}

$$
\begin{gathered}
\text { Rosdiana }^{1} \text {, Sumiyati }{ }^{2} \text {, Nurul Azharia }{ }^{3}, \text { Hijrah }^{4} \\
(x x i+66 \text { page }+9 \text { table }+4 \text { picture }+8 \text { attachments })
\end{gathered}
$$

Background: Most maternity mothers experience pain during childbirth, but the intensity of this pain is different for each woman. Non-pharmacological methods are the method most often used 
to reduce pain. From the data obtained at Pekkabata Community Health Center in 2016 the number of mothers gave birth to 450 people and in 2017 from October to December as many as 29 mothers gave birth so the researchers were interested in examining the description of maternal knowledge about Pneumonia in infants at Pekkabata Puskemas in 2016.

Objective: To determine the effect of giving warm water compresses to reduce pain in mothers giving birth at Pekkabata Health Center.

Research Method: quasy experimental design / quasi-experimental is used, which is an experimental study conducted in one group called the experimental group without a comparison group or control group (Arikunto, 2012). The population in this study all mothers giving birth at the Pekkabata Health Center in 2017 counted 29 October. The sample selection in this study is using Accidental Sampling, which is sampling that is done by chance to meet. The number of samples in this study were 29 respondents.

The results of the study: Statistical test using Marginal Homogeneity Test also supports the data in the table where from the results obtained pvalue $=0,000$ (value $<0.05$ ) then this means that $\mathrm{Ha}$ is accepted and $\mathrm{HO}$ is rejected can be concluded that there is an effect of giving warm water compresses to reduce pain in mothers give birth at Pekkabata Health Center.

Conclusion: there is a reduction in pain after warm water compresses on the delivery mother.

Keywords: Influence, Compress warm water, pain, maternity.

Bibliography: 17 books + 6 internet (2008-2017)

\section{PENDAHULUAN}

\section{Latar Belakang}

\section{Program pembangunan}

kesehatan di Indonesia dewasa ini masih diprioritaskan pada upaya peningkatan derajat kesehatan yaitu ibu hamil, bersalin dan bayi pada masa perinatal.Hal ini ditandai dengan tingginya Angka Kematian ibu (AKI) dan Angka kematian bayi (AKB) (Kementerian Kesehatan RI, 2015).

AKI di Indonesia saat ini masih cukup tinggi. Berdasarkan hasil survei demografi kesehatan Indonesia ( SDKI) pada tahun 2012, AKI di Indonesia masih tinggi yaitu sebesar 359 orang per 100.000 kelahiran hidup. Sedangkan AKB di Indonesia tahun 2012 sebesar 32 per 1000 kelahiran hidup (Kementerian Kesehatan RI, 2015).

Nyeri dan ketegangan emosional meningkatkan kadar kortisol dan katekolamin yang dapat mempengaruhi lama dan intensitas persalinan. Rasa nyeri saat persalinan bisa meningkatkan tekanan darah, denyut Jantung janin meningkat dan konsentrasi ibu selama persalinan menjadi terganggu. Semua itu akan berefek buruk terhadap kelancaran persalinan

Beradasarkan data WHO pada tahun 2010 kasus sectiocaesar tanpa indikasi di amerika berjumlah 30,3\% . sedangkan di Indonesia berjumlah $6,8 \%$. Data tersebut menunjukkan bahwa kejadian permintaan untuk melakukan secticaesaria cukup tinggi oleh sebab itu sebagai bidan kita harus melakukan upaya untuk mengurangi rasa nyeri sehingga kejadian sectiocaesaria tanpa indikasi dapat dikurangi. (WHO,2010)

$$
\text { Upaya untuk mencegah }
$$
kematian ibu dilakukan dengan merencanakan program safemotherhood 
yaitu meningkatkan pelayanan keluarga berencana, asuhan kehamilan, persalinan yang bersih dan aman serta pelayanan obstetrik(Johariyah, 2012). Kehamilan, persalinan dan masa nifas merupakan peristiwa fisiologis dalam setiap perkembangan seorang wanita menjadi ibu.Namun, kematian ibu berkaitan dengan komplikasi pada saat kehamilan dan persalinan.(Suririnah, 2010).

Persalinan adalah usaha yang dilakukan oleh rahim ketika bayi akan dilahirkan. Selama persalina, rahim berkontraksi dan mendorong bayi ke bawah sampai keleher rahim.Dorongan ini membuka leher rahim. Setelah leher rahim mencapai pembukaan lengkap, kontraksi dan dorongan ibu akan menggerakkan sibayikebawah dan keluar beberapa hari (Simkin,2008).

Sebagian besar ibu bersalin mengalami rasa nyeri pada waktu melahirkan, tetapi intensitasnya rasa nyeri ini berbeda pada setiap ibu bersalin. Hal ini sering dipengaruhi oleh psikologis ibu saat bersalin (rasa takut dan berusaha melawan persalinan) serta ada tidaknya dukungan dari orang sekitar selama proses persalinan.

Peristiwa fisiologis pada saat persalinan terkadang dapat menimbulkan trauma pada ibu karena nyeri yang dialaminya. Beberapa ibu bahkan ada yang trauma untuk hamil dan melahirkan lagi karena takut akan mengalami nyeri yang sama. Bagi ibu yang pernah melahirkan, nyeri persalinan merupakan nyeri yang paling menyakitkan apalagi bagi ibu-ibu yang baru pertama kali merasakannya (Kementerian kesehatan RI, 2015)

Rasa nyeri pada persalinan dalam hal ini adalah nyeri kontraksi uterus yang dapat mengakibatkan peningkatan aktifitas sistem saraf simpatis, perubahan tekanan darah, denyut jantung, pernafasan dan apabila tidak segera diatasi maka akan meningkatkan rasa khawatir, tegang, takut dan stress. Nyeri pada ibu bersalin juga menyebabkan meningkatnya kadarkatekolamin atau hormon stress seperti epinefrin dan kortisol. Peningkatan kadarkatekolaminatau hormon strees dapat mengurangi kemampuan tubuh menahan rasa nyeri (Maryunani, 2010)

Pengelolaan nyeri persalinan merupakan salah satu tujuan utama perawatan bersalin.Tujuan keseluruhan dalam pengobatan nyeri adalah mengurangi nyeri sebesar-besarnya dengan kemungkinan efek samping paling kecil.

Penatalaksanaan dalam mengatasi nyeri nyeri persalinan berdasarakan penelitian di sembilan rumah sakit di Amerika Serikat tahun 1996 sebanyak 4.171 pasien yang persalinannya ditolong oleh perawatbidan menggunakan beberapa tipe penatalaksanaan nyeri untuk mengatasi nyeri. Ibu bersalin tersebut sekitar $90 \%$ diantaranya memilih metode non farmakologis untuk mengatasi nyeri (Manurung, 2011).

Metode non farmakologis merupakan suatu pendekatan yang digunakan untuk menghilangkan nyeri 
tanpa menggunakan obat-obatan.Terapi kompres panas dan dingin merupakan salah satu metode non farmakologis untuk mengatasi nyeri.Terapi ini perlu diberikan bagi semua ibu melahirkan sebagai salah satu intervensi terapi nyeri di pelayanan kesehatan yakni rumah sakit, puskesmas maupun klinik bersalin (Dolatian, 2011).Metode non farmakologis merupakan metode yang paling sering digunakan untuk mengurangi nyeri.Metode ini mempunyai resiko yang sangat rendah, bersifat murah, simpel, efektif, tanpa efek yang merugikan dan dapat meningkatkan kepuasan selama persalinan (Berman, 2009).

Terapi kompres air hangat merupakan salah satu terapi magemen nyeri persalinan selain terapi alternatif lainnya seperti pemberian psikoedukasional, terapibiofeedback, terapiendorphin, gate kontroldan sensorytransforamationI.

Kompres hangat dapat dilakukan di bawah punggung, pangkal paha, perut atau bawah bahu selama persalinan. Prinsip kerja kompres hangat secara konduksi di mana terjadi perpindahan panas dari media panas ke dalam perut yang akan melancarkan sirkulasi darah dan menurunkan ketegangan otot sehingga akan menurunkan nyeri pada wanita disminore primer juga pada kala persalinan, karena pada wanita ini mengalami kontraksi uterus dan kontraksi otot polos (Prawirohardjo, 2011).
Kompres hangat yang dilakukan di daerah sakrum ibu (punggung bawah) terbukti dapat mengurangi nyeri persalinan. Melalui tehnik kompres hangat selama proses persalinan dapat mempertahankan komponen sistem vaskuler dalam keadaan vasolidatasi sehingga sirkulasi darah ke otot panggul menjadi homeostatis serta dapat mengurangi kecemasan dan ketakutan serta beradaptasi dengan nyeri selama proses persalinan.

Umumnya ibu bersalin mengalami ketidaknyamanan berupa nyeri yang diakibatkan oleh peningkatan spasme (kekakuan) otototot, membuat ibu inpartu pada fase ini membutuhkan asuhan yang tepat berupa pemenuhan rasa nyaman(bebas nyeri) dalam proses persalinan. Kemudian kompres hangat bermanfaat untuk mereleksasikan otot-otot yang mengalami spasme(kekauan) pada proses persalinan. Panas juga merangsang serat saraf yang menutup gerbang sehingga transmisi implus nyeri ke medullaspinaslis dan otak dapat dihambat. Di samping itu, dengan adanya penguranga nyeri persalinan akan mempertahankan bebrapa sensasi kontraksi uterus dan kemampuan untuk mengejan (Dolatian, 2011)

Hasil penelitian Manurung (2011) mengenai pengaruh tehnik pemberian komres hangat terhadap perubahan skala nyeri persalinan pada klien primigravida menunjukkan bahwa pemberian terapi kompres hangat sangat efektif dalam menurunkan nyeri persalinan. Sedangkan hasil penelitian 
Khofia (2014) perbedaan efektifitastehnik pijat dan kompres air hangat terhadap nyeri persalinan kala I fase aktif di wilayah kerja puskesmsa bergas kabupaten semarang menunjukkan bahwa ada perbedaan sebelum dan sesudah diberikan kompres hangat ibu bersalin kala I fase aktif.

Dari data yang diperoleh di PuskesmasPekkabatapada tahun 2016 jumlah ibu bersalin sebanyak 450 orang dan pada tahun 2017 terhitungsejakbulanOktober-Desember sebanyak 29ibu bersalin.

\section{METODE PENELITIAN}

\section{Rancangan Penelitian}

Jenis penelitian yang digunakan adalah quasy eksperimental design/eksperimen semu, yaitu penelitian eksperimen yang dilaksanakan pada satu kelompok saja yang dinamakan kelompok eksperimen tanpa ada kelompok pembanding atau kelompok
Hasil studi pendahuluan yang dilakukan penulis di puskesmas pekkabata terhadap $6 \mathrm{ibu}$ bersalin terdapat 3 orang $(50 \%)$ ibu inpartu yang menyatakan merasakan rasa nyaman dalam persalinan dan ibu diberi kompres air hangat dan 3 orang (50\%) lainnya menyatakan nyeri sekali pada saat proses persalinanya dan ibu tidak di beri kompres air hangat.

Oleh karena itu penulis tertarik untuk mengambil judul penelitian "Pengaruh Pemberian kompres air hangat terhadap pengurangan rasa nyeri pada ibu bersalin di Puskesmas Pekkabata"

kontrol (Arikunto, 2012). Sesuai dengan jenis penelitian yang dikemukakan di atas maka indikator-indikator penelitian dapat disusun pengukurannya sebagai bahan analisis statistic. Pada penelitian ini peneliti ingin mengetahui Pengaruh Pemberian kompres air hangat terhadap pengurangan rasa nyeri pada ibu bersalin di Puskesmas Pekkabata

\section{HASIL PENELITIAN DAN PEMBAHASAN Karakteristik responden}

Pendidikan

Tabel 4.1

Distribusi Frekuensi Pendidikan ibu bersalin di Puskesmas Pekkabata

\begin{tabular}{|c|c|c|}
\hline Pendidikan & F & \% \\
\hline SD & 11 & 37,9 \\
\hline SMP & 7 & 24,1 \\
\hline SMU & 6 & 20,7 \\
\hline Perguruan Tinggi & 5 & 17,2 \\
\hline Total & $\mathbf{2 9}$ & $\mathbf{1 0 0 , 0}$ \\
\hline
\end{tabular}

Sumber: Data Primer 2018 
Berdasarkan tabel 4.1 dapat diketahui bahwa kisaran pendidikan ibu bersalin di Puskesmas Pekkabata SD dengan tingkat tertinggi yaitu sebanyak

Pekerjaan
$11(37,9 \%)$ responden, SMP sebanyak 7 (24,1\%), SMU sebanyak 6 (20,7\%), dan Pendidikan Perguruan tinggi sebanyak $5(17,2 \%)$

Tabel 4.2

Distribusi Frekuensi Pekerjaan ibu bersalin di Puskesmas Pekkabata

\begin{tabular}{|c|c|c|}
\hline Pekerjaan & F & \% \\
\hline IRT & 14 & 48,3 \\
\hline Swasta & 12 & 41,4 \\
\hline PNS & 3 & 10,3 \\
\hline Total & $\mathbf{2 9}$ & $\mathbf{1 0 0 , 0}$ \\
\hline
\end{tabular}

Sumber: Data Primer 2018

Berdasarkan tabel 4.2

dapat diketahui bahwa kisaran pekerjaan ibubersalin di Puskesmas Pekkabata adalah IRT dengan tingkat tertinggi yaitu

Umur sebanyak 14(48,3\%) responden, pekejaan Swasta sebanyak 12 $(41,4 \%)$ responden dan pekerjaan PNS sebanyak 3 (10,3\%) responden

Tabel 4.3

Distribusi Frekuensi umur ibu bersalin di Puskesmas Pekkabata

\begin{tabular}{|c|c|c|}
\hline Umur & F & \% \\
\hline$<25$ tahun & 16 & 55,2 \\
\hline$>25$ tahun & 13 & 44,8 \\
\hline Total & $\mathbf{2 9}$ & $\mathbf{1 0 0 , 0}$ \\
\hline
\end{tabular}

Sumber: Data Primer 2018 
Berdasarkan tabel 4.3

dapat diketahui bahwa kisaran umur ibu bersalin di Puskesmas Pekkabata adalah $<25$ tahun dengan tingkat tertinggi yaitu sebanyak 16 $(55,2 \%)$ responden, dan $>25$ tahun sebanyak 13 (44,8\%) responden

\section{Analisa Univariat}

Tabel 4.4

Distribusi Frekuensi tingkat nyeri sebelum kompres air hangat di Puskesmas Pekkabata

\begin{tabular}{|c|c|c|}
\hline Tingkat nyeri & F & \% \\
\hline Ringan & 2 & 6,9 \\
\hline Sedang & 4 & 13,8 \\
\hline Berat & 23 & 79,3 \\
\hline Total & $\mathbf{2 9}$ & $\mathbf{1 0 0 , 0}$ \\
\hline
\end{tabular}

Sumber: Data Primer 2018

Berdasarkan tabel

tertinggi sebanyak 23

4.4dapat diketahui bahwa

kisaran tingkat nyeri

sebelum kompres air

hangat di Puskesmas

Pekkabata adalah nyeri

berat dengan tingkat

$(79,3 \%)$ responden, nyeri sedang sebanyak 4 $(13,8 \%)$ responden dan pada nyeri ringan sebanyak2 (6,9\%) responden.

Tabel 4.5

Distribusi Frekuensi tingkat nyeri sesudah kompres air hangat di Puskesmas Pekkabata

\begin{tabular}{|c|c|c|}
\hline Tingkat nyeri & F & \% \\
\hline Ringan & 27 & 93,1 \\
\hline Sedang & 1 & 3,4 \\
\hline Berat & 1 & 3,4 \\
\hline Total & $\mathbf{2 9}$ & $\mathbf{1 0 0 , 0}$ \\
\hline
\end{tabular}

Sumber: Data Primer 2018 
Berdasarkan tabel 4.5dapat diketahui bahwa kisaran tingkat nyeri sesudah kompres air hangat di Puskesmas Pekkabata adalah nyeri ringan dengan tingkat tertinggi sebanyak $27 \quad(93,1 \%)$ responden, nyeri sedang sebanyak $1(3,4 \%)$ responden dan pada nyeri berat sebanyak1 $(3,4 \%)$ responden.

\section{Analisa Bivariat.}

\section{Pengaruh Pemberian kompres air hangat terhadap pengurangan rasa nyeri pada ibu bersalin di Puskesmas Pekkabata.}

Untuk menguji Pengaruh Pemberian kompres air hangat terhadap pengurangan rasa nyeri pada ibu bersalin di Puskesmas Pekkabata digunakan uji Marginal Homogeneity Test adalah statistik non parametris yang di gunakan untuk melihat apakah perbedaan atau perubahan antara 2 peristiwa sebelum dan sesudahnya. dapat dilihat pada tabel 4.6 berikut ini :

\section{Tabel 4.6}

Marginal Homogeneity Test

\begin{tabular}{|l|r|}
\hline & \multicolumn{2}{|c|}{$\begin{array}{c}\text { Sebelum kompresair } \\
\text { hangat \& sesudah } \\
\text { kompres air hangat }\end{array}$} \\
\hline DistinctValues & 3 \\
Off-Diagonal Cases & 26 \\
Observed MH Statistic & 74,000 \\
Mean MH Statistic & 50,500 \\
Std. Deviationof MH & 4,717 \\
Statistic & 4,982 \\
Std. MH Statistic &, 000 \\
Asymp. Sig. (2-tailed) & 3 \\
DistinctValues & \\
\hline
\end{tabular}

Sumber : Data Primer 2018

Hasil

menggunakan

pengujian

Marginal

Homogeneity Test juga mendukung data pada table dimana dari hasil diperoleh pvalue $=0,000$ (Pvalue $<0,05)$ maka ini berarti $\mathrm{H}_{\mathrm{a}}$ di terima dan $\mathrm{H}_{0}$ ditolak dapat disimpulkan bahwa ada Pengaruh Pemberian kompres air hangat terhadap pengurangan rasa nyeri pada ibu bersalin di Puskesmas Pekkabata

\section{PEMBAHASAN}


Tingkat nyeri sebelum kompres air hangat

Berdasarkan tabel 4.4dapat diketahui bahwa kisaran tingkat nyeri sebelum kompres air hangat di Puskesmas Pekkabata adalah nyeri berat dengan tingkat tertinggi sebanyak 23 (79,3\%) responden, nyeri sedang sebanyak4 $(13,8 \%)$ responden dan pada nyeri ringan sebanyak2 $(6,9 \%)$ responden.

Berdasarkan asumsi peneliti nyeri yang dirasakan ibu bersalin selain disebabkan karena kontraksi. Ibu bersalin juga merasa cemas akan persalinannya. Dimana sebagian ibu bersalin tidak di dampingi oleh suaminya sehingga ibu tidak memiliki semangat.

Menurut judha (2012) rasa nyeri pada ibu bersalin adalah manifestasi dari adanya kontraksi (pemendekat) otot rahim. Kontraksi inilah yang menimbulkan rasa sakit pada pinggang, daerah perut dan menjalar kearah paha. Kontraksi ini menyebabkan adanya pembukaan mulut rahim (serviks). Dengan adanya pembukaan serviks ini maka akan menjadi persalinan.

Rasa nyeri muncul akibat respon psikis dan refleks fisik. Kualitas rasa nyeri fisik dinyatakan sebagai tusukan, nyeri terbakar, rasa sakit, denyutan, sensasi rasa tajam, rasa mual dan kram. Ketika ibu merasa sangat takut maka secara otomatis otak mengatur dan mempersiapkan tubuh untuk merasa sakit, sehingga rasa sakit saat persalinan akan lebih terasa (siregar,2012).

Menurut wahyuni menyebutkan bahwa nyeri yang paling dominan dirasakan pada saat persalinan. Secara fisiologi, nyeri persalinan mulai timbul pada persalinan kala I fase laten dan fase aktif, timbulnya nyeri disebabkan oleh adanya kontraksi uterus yang mengakibatkan dilatasi dan penipisan serviks. Dengan demikian bertambahnya baik volume maupun frekuensi kontraksi uterus, nyeri yang dirasakan akan bertambah kuat dan puncak nyeri terjadi pada fase aktif. Sebagian besar nyeri diakibatkan oleh dilatasi serviks dan regangan segmen bawah rahim, kemudian akibat distensi mekanik, regangan dan robekan selama kontraksi. Intensitas nyeri berhubungan dengan kekuatan kontraksi dan tekanan yang ditimbulkan.

\section{Tingkat nyeri sesudah kompres air hangat}

Berdasarkan tabel 4.5dapat diketahui bahwa kisaran tingkat nyeri sesudah kompres air hangat di Puskesmas Pekkabata adalah nyeri ringan dengan tingkat tertinggi sebanyak $27(93,1 \%)$ responden, nyeri sedang sebanyak $1(3,4 \%)$ responden dan pada nyeri berat sebanyak1 $(3,4 \%)$ responden.

Berdasarkan asumsi peneliti bahwa setelah diberikan kompres air 
hangat pada ibu bersalin terjadi penurunan nyeri. Ibu bersalin mengatakan nyerinya mulai berkurang. Ibu merasa lebih nyaman dari sebelumnya. Kompres hangat ini terbukti efektif dalam menurunkan nyeri persalinan dan membantu mengurangi rasa sakit saat permulaan persalinan. Secara keseluruhan berdasarkan apa yang peneliti observasi, semua responden rata-rata mengatakan bahwa nyeri persalinan yang dirasakannya berkurang walaupun respon yang diberikan berbeda-beda.

Penggunaan kompres hangat untuk area yang tegang dan nyeri dianggap mampu meredakan nyeri. Hangat mengurangi spasme otot yang disebabkan oleh iskemia yang merangsang neuron yang memblok transmisi lanjut rangsang nyeri menyebabkan vasolidatasi yang peningkatan aliran darah kearea yang dilakukan pengompresan (Walsh,2008).

Pemberian kompres air hangat pada punggung bawah wanita di area tempat kepala janin menekan tulang belakang akan mengurangi rasa nyeri persalinan, panas akan meningkatkan sirkulasi ke area tersebut sehingga memperbaiki anoksia jaringan yang disebabkan oleh tekanan. Panas dapat disalurkan oleh konduksi (botol air panas, bantalan pemanas listrik, lampu, kompres hangat kering dan lembab) atau konversi (ultrasonografi, diatermi).
Sebagian besar ibu bersalin mengalami rasa nyaman setelah diberikan kompres hangat. Kompres hangat yang diberikan pada punggung bagian bawah ibu diarea tempat kepala janin menekan tulang belakang kepala akan mengurangi rasa nyeri, hangat akan meningkatkan sirkulasi ke area tersebut sehingga memperbaiki anoksia jaringan yang disebabkan oleh tekanan.

Hasil penelitian ini di dukung dengan penelitian yang dilakukan oleh siregar (2012), penurunan skala nyeri sebelum dan sesudah dilakukan terapi kompres air hangat di Klinik Nirmala Medan menunjukkan adanya pengaruh yang signifikan sebelum dan sesudah pemberian kompres air hangat pada ibu bersalin kala I fase aktif dengan PValue 0,000 .

Hasil penelitian ini juga memperkuat dengan penelitian sebelumnya yang dilakukan oleh manurung (2011) tehnik kompres air hangat selama proses persalinan dapat mempertahankan komponen sistem vaskuler dalam keadaan vasoliditasi sehingga sirkulasi darah keotot panggul menjadi homeostatis serta dapat mengurangi kecemasan dan ketakutan serta beradaptasi dengan nyeri selama proses persalinan.

Terapi kompres hangat telah terbukti meningkatkan kemampuan ibu untuk mentoleransi nyeri selama melahirkan karena efek dari panas. Terapis fisik dan profesional kesehatan lainnya telah menggunakan terapi hangat untuk mengurangi berbagai 
bentuk rasa sakit kronis. Dengan mengompres di daerah sakrum ibu (punggung bawah) dapat mengurangi nyeri persalinan.

Pengaruh Pemberian kompres air hangat terhadap pengurangan rasa nyeri pada ibu bersalin di Puskesmas Pekkabata

\begin{abstract}
Penelitian ini dilakukan
dengan melakukan intervensi terhadap ibu bersalin dengan melakukan pemberian kompres hangat di bagian punggung bawah.Berdasarkan hasil penelitian yang diperoleh yaitu terlihat adanya penurunan intensitas nyeri pada ibu bersalin. Sebelum dilakukan intervensi pemberian kompres hangat berdasarkan intensitas nyeri yang dialami oleh responden yaitu sebagian besar23 $(79,3 \%)$ responden mengalami nyeri berat dan setelah dilakukan intervensi pemberian kompres hangat27 (93,1\%) responden mengalami nyeri ringan.
\end{abstract}

$\begin{array}{cc}\text { Hasil } & \text { pengujian } \\ \text { menggunakan } & \text { Marginal }\end{array}$

Homogeneity Test juga mendukung data pada table dimana dari hasil diperoleh pvalue $=0,000$ (Pvalue $<0,05$ ) maka ini berarti $\mathrm{H}_{\mathrm{a}} \mathrm{di}$ terima dan $\mathrm{H}_{0}$ ditolak dapat disimpulkan bahwa ada Pengaruh Pemberian kompres air hangat terhadap pengurangan rasa nyeri pada ibu bersalin di Puskesmas Pekkabata.

Hasil penelitianini juga memperkuat penelitian sebelumnya yang dilakukan oleh Siregar (2012) tentang pemberian kompres hangat pada ibu bersalin kala I berpengaruh terhadap pengurangan nyeripersalinan di Klinik Nirmala Medan dengan nilai rata-rata sebelum intervensi mencapai $8,40 \%$ dan sesudah intervensinilai rata-rata menjadi 4,75\%. Bahwa kompres hangat bermanfaat untuk meningkatkan suhu kulit lokal, melancarkan sirkulasi darah dan menstimulasi pembuluh darah, mengurangi spasmeotot dan meningkatkan ambang nyeri, menghilangkan sensasi rasa nyeri, merangsang peristaltikusus, pengeluaran getahra dan serta memberikan ketenangan dan kenyamanan pada ibu inpartu. Hasil penelitian tersebut menunjukkan ada pengaruh yang signifikan pemberian kompres hangat terhadap pengurangan nyeri persalinan kala I dengan nilai $\mathrm{p}$ value $=0,000, \mathrm{p}$ value $<0,05$.

Temuan di atas sejalan dengan hasil penelitianYani (2012) Pengaruh Pemberian Kompres Air Hangat terhadap Rasa Nyaman dalam Proses Persalinan Kala I Fase Aktif, dengan nilai Z-2,049 $<\mathrm{Z}$ table dengan Asymp sig : 0,04 yang menunjukkan bahwa pemberian kompres air hangat yang diberikan pada punggung bawah wanita selama 20 menit di area tempat kepala janin menekan tulang belakangakan mengurangi nyeri persalinan, panas akan meningkatkan sirkulasike area tersebut sehingga memperbaiki 
anoksia jaringan yang disebabkan oleh tekanan . Panas dapat disalurkan melalui konduksi (botol air panas, bantalan pemanas listrik, lampu, kompres hangat kering dan lembab) atau konversi (Ultrasonografi, diatermi).

Sebagian besar ibu inpartu mengalami rasa nyaman setelah diberikan kompres hangat. Kompres hangat yang diberikan pada punggung bagian bawah ibu di area tempat kepala janin menekan tulang belakang kepala akan mengurangi rasa nyeri, hangat akan meningkatkan sirkulasi ke area

\section{KESIMPULAN DAN SARAN}

Kesimpulan

Berdasarkan hasil penelitian dan pembahasan, dapat penulis simpulkan sebagai berikut :

Tingkat nyeri sebelum kompres air hangat di Puskesmas Pekkabatadalam kategori nyeri berat sebanyak23 $(79,3 \%)$ responden.

Tingkat nyeri sesudah kompres air hangat di Puskesmas Pekkabatadalam kategori nyeri ringan sebanyak27 $(93,1 \%)$ responden.

Hasil pengujian menggunakan Marginal Homogeneity Test juga mendukung data pada table dimana dari hasil diperoleh pvalue $=0,000$ (Pvalue $<0,05$ ) bahwa ada pengurangan rasa nyeri pada ibu bersalin dengan metode kompres air hangat di Puskesmas Pekkabata tersebut sehingga memperbaiki anoksia jaringan yang disebabkan oleh tekanan.

Kompres hangat ini terbukti efektif dalam menurunkan nyeri persalinan dan membant umengurangi rasa sakit saat permulaan persalinan. Secara keseluruhan berdasarkan apa yang telah peneliti observasi, semua responden rata-rata mengatakan bahwa nyeri persalinan yang dirasakannya berkurang walaupun respon yang diberikannya berbedabeda.

\section{Saran}

\section{Bagi Puskesmas.}

Mendukung bidan dalam memberikan terapi kompres air hangat dengan melengkapi fasilitas yang dibutuhkan misalnya buli-buli, thermometer dan air panas.

\section{Bagi Institusi Pendidikan.}

Penelitimenyarankan agar hasil penelitian ini dapat dijadikan referensi pendukung secara ilmiah dalam penelitian dan keilmuan selanjutnya.

\section{Bagi Peneliti}

Mampu mengaplikasikan ilmu yang telah di dapat mengenai pemberian terapi kompres air hangat terhadap penurunan skala nyeri pada ibu bersalin, menambah wawasan dalam bidang penelitian dan sebagai masukan dalam rangka meningkatkan profesionalismedalam memberikan pelayanan pada pasien.

\section{Bagi masyakat}


Hasil penelitian ini dapat di gunakan sebagai bahan masukan bagi masyarakat dalam menambah pengetahuan tentang pentingnya terapi kompres air hangat terhadap penurunan intensitas nyeri khususnya pada ibu bersalin.

\section{DAFTAR PUSTAKA}

A. aziz alimul hidayat. (2008). Riset keperawatan dan teknik penulisan ilmiah. (nurchasanah, Ed.) (ke 2). jakarta: Salemba Medika.

Ai Rukiah Yeyeh dkk. 2014. Asuhan Kebidanan II Persalian. Jakarta. Salemba Medika

Andari. (2015). konsep dan proses keperawatan nyeri jakarta: Salemba Medika.

Ari Sulistyawati \& Esti Nungraheni.Asuhan Kebidanan Pada Ibu Bersalin.Jakarta : Salembang Medika. 2013 Cetakan Kelima

Dinas Kehatan Kabupaten Polewali Mandar.2014.Profil Kesehatan Kabupaten Polewali Mandar

Depkes RI. (2015). Penyebab Kematian Ibu Selama Kehamilan.Diambil 5 April 2018, dari http.//www.depkes.go.id

Felina Mutia dkk 2015. Pengaruh Kompres Panas Dan Dingin Terhadap Penurunan Nyeri Kala I Fase Aktif Persalinan Fisiologis Ibu Primi Parah, [http://Jurnal.fk.unand.ac.id] diakses pada tanggal 16 januari 2018

Indiarti. 2015. Panduan terbaik Kehamilan,Persalian, dan

\section{Bagi peneliti selanjutnya}

Diharapkan

penelitian selanjutnya untuk mengguanakan metode-metode lainnya untuk mengurangi nyeri persalinan sebagai bahan perbandingan dalam penelitian.

perawatan bayi. Yogyakarta: Indoliterasi

Maulana Mirza. 2016. Panduan lengkap Kehamilan. Yogyakarta : Katahati

Mochtar Rustam. 2011. Sinopsis Obstetri Edisi 3. Jakarta:Buku Kedokteran EGC

Manurung Suryani dkk. 2013. Pengaruh Tehnik Pemberian Kompres Air Hangat Terhaap Peerubahan Skala Nyeri Persalinan Pada Klien Primigravida.Jakarta : Jurnal Healt Quality[http"//poltekesjakarta.ac.id]

Maryunani, A. (2010). Nyeri dalam Persalinan. Trans Info Media, Jakarta,6-10+40-53 hlm.

Notoatmojo. (2014) Metode Penelitian Kesehatan, Jakarta: Rineka Cipta

Oktarina Mika.2016.buku Ajar Asuhan Kebidanan Persalinan Dan Bayi Baru Lahir.Yogyakarta:Cv Budi Utama

Prawiroharjo.(2013). Ilmu Kebidanan.Yayasan Bina Pustaka Sarwono Prawiroharjo : Jakarta

Sastroasmoro,dkk.2011.Dasar-dasar metodologi penelitian klinis Edisi ke4. Jakarta: Sagung Seto 
Simkin, P.,dkk(2015) Panduan lengkap kehamilan, melahirkan, dan bayi. Jakarta:Arcanrik

Suhaimi. 2014. Program Perencanaan Persalinan. [http;//Blogadhaedelweiis.blogspot.com/2015/09 /program-perencanaan persalinan.html] diakses pada tanggal 18 Januari 2018 Pukul 15.30 wita.

Siregar, Yusniar. (2012).Pemberian Kompres Hangat pada Ibu Bersalin Kala I Berpengaruh terhadap Pengurangan Nyeri Persalinan di Klinik Bersalin Nirmala Medan. http://uda.ac.id/jurnal/files/Judul\% yusniar dosen\%20poltekkes $\% 20$ kemenkes\%20mdan.pdf.

Diakses pada tanggal 23 april2016

Tresnawati F. 2012. Asuhan Kebidanan Jilid I. Jakarta : PT.Prestasi Pustaka Raya

Yani, Khasanah:2013.Pengaruh Pemberian Kompres Air Hangat Terhadap rasa nyaman dalam proses persalinan kala I fase aktif. FIK Unipdu,[Http://www.journal.unipdu. ac.id]

Yuliantu,,Laily.2013 Penanganan Nyeri Persalinan dengan metode non farmakologi.Bayumedia:Malang 